\title{
Effect of Fins Arrangement on Thermal Performance in Microelectronics Devices
}

\author{
EKPU, M \\ Department of Mechanical Engineering, Delta State University Abraka, Oleh Campus, Delta State, Nigeria. \\ Email: ekpum@delsu.edu.ng
}

\begin{abstract}
Heat sink fins arrangement are important in heat management in microelectronics devices because it helps in the dissipation of heat from the chip level device to the environment and provide an efficiently working device. In this light, investigation was conducted on the effect of fins arrangement on thermal performance in microelectronics devices using the ANSYS finite element design software. The results obtained showed a maximum temperature range of between $95.27-126.79{ }^{\circ} \mathrm{C}$, thermal resistance of $1.2-1.8 \mathrm{~K} / \mathrm{W}$, and thermal efficiency of $15-$ $37 \%$. The results demonstrated that, the arrangement of heat sink fins largely affects the thermal resistances and efficiencies of the microelectronic device. In addition, the A1 rectangular fins arrangement exhibited better thermal capabilities over the other fins arrangements investigated. This research can aid the development of future heat sinks to accommodate customer demands.
\end{abstract}

\section{DOI: https://dx.doi.org/10.4314/jasem.v22i11.14}

Copyright: Copyright (C) 2018 Ekpu. This is an open access article distributed under the Creative Commons Attribution License (CCL), which permits unrestricted use, distribution, and reproduction in any medium, provided the original work is properly cited.

Dates: Received: 15 October 2018; Revised: 24 November 2018; Accepted 30 November 2018

Keywords: heat transfer; fin arrangement; microelectronics

Heat management in small electronic packages has become a serious problem in microelectronics industries. This is as a result of the excessive heat generated by power packed devices. Consumers keeps demanding efficient and portable devices which in turn increases the heat dissipation of the devices. Researchers such as (Ekpu et al 2011; Wan et al 2011) have reported on devices that can be used to effectively remove the excess heat generated by the electronic devices. Numerical analysis have been used over the years to analyse heat sink effectiveness in electronic devices. Yang and Peng (2008) found in their study that, in order to reduce the junction temperature, the fin height closer to the centre of the heat sink will need to be increased. This study was carried out with a pinfin heat sink with un-uniform fin height design. The transfer of heat in electronic packages with the aid of heat sinks and their configurations have been studied by researchers over years (Yang and Peng, 2009; Maveety and Jung, 2002; Kreutz, 2000; Luo et al, 2009; Kulkarni and Das, 2005). However, the study conducted by Naphon and Sookkasem (2007), demonstrated that there is a strong relationship between numerical and experimental results in terms of heat transfer in tapered cylinder pin fin heat sinks. Also, the numerical results gotten by Maveety and Jung (2002) demonstrated similar relationship with experimental results. This investigation is centred on the effect of fins arrangement on thermal performance in microelectronics devices. The flat plate rectangular fins arrangement was the focus because it is the most used type of heat sink in sure devices. This research is aimed at analysing different heat sink arrangements in a single study.

\section{MATERIALS AND METHODS}

Model Description: The models in this study were created using ANSYS finite element design software. In this study, ten different rectangular flat plate fins arrangement (A1-A10) were considered. Each of the model comprised of a chip with a $20 \times 20 \times 1 \mathrm{~mm}^{3}$ dimension and a heat sink base of $40 \times 40 \times 3 \mathrm{~mm}^{3}$. The number of fins and length were determined by the arrangement or pattern of the fins. However, each fin has a height and thicknes of $10 \mathrm{~mm}$ and $2 \mathrm{~mm}$ respectively. A diagramatic representation of the designed rectangular flat plate heat sink fins showing the top view is shown in Fig. 1.

Boundary Conditions, Loads and Materials: In this study, aluminium heat sinks and silicon chips with thermal conductivities of $237.5 \mathrm{~W} / \mathrm{mK}$ and $148 \mathrm{~W} / \mathrm{mK}$ (derived from in-built ANSYS material models) respectively were used. The steady state thermal analyses was carried out to show the capability of the ANSYS software used. This investigation neglected heat loss due to radiation and considered conduction and convection modes of heat transfer. A heat source of $60 \mathrm{~W}$ was used in the study to replicate the amount of heat consumed by microelectronics devices. In 
addition, a convective coefficient for natural convection was applied to the heat sinks. The thermal conduction in this study is governed by the Fourier equation given in (Ekpu et al, 2012; Incropera et al, 2007). While the convection equation of the outer surfaces of the heat sink is given as:

$$
n\left(k \frac{d T}{d x}\right)=h\left(T_{a}-T\right)
$$

Where $n$ is the outward surface normal, $h$ is the coefficient of heat transfer, and $T_{a}$ is the surrounding temperature. The maximum temperature of the fins, thermal resistances of the fins, and thermal efficiency of the fins were investigated in the study.

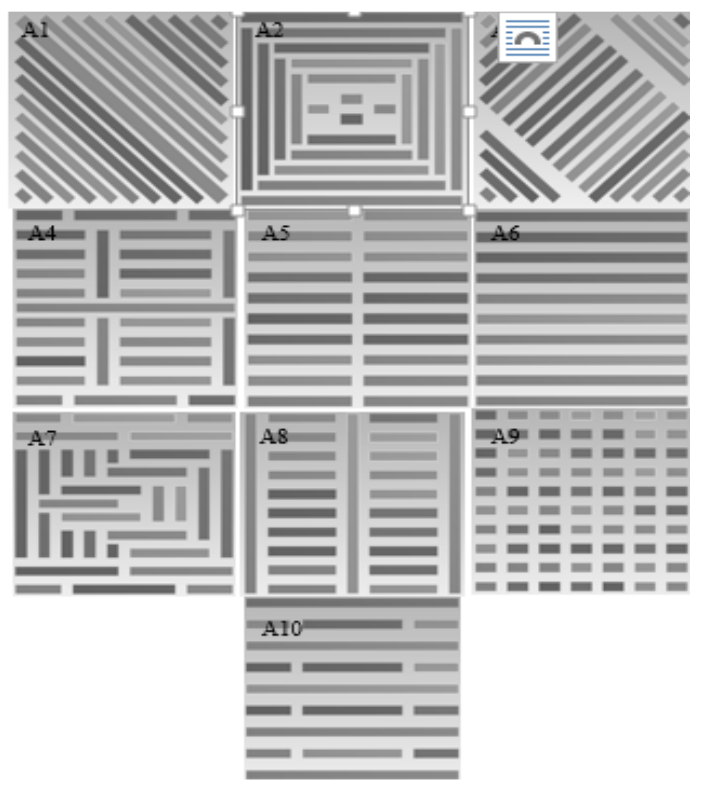

Fig. 1: Fins Arrangement

\section{RESULTS AND DISCUSSIONS}

Fins Arrangement and Conduction Profile: The temperature contour plots of the top view of the heat sink fins studied are presented in Fig. 2. From Fig. 2, the contour plots of temperature distributions showed that the heat concentration is highest around the centre of the heat source. This is consistent with the results published by Ekpu et al (2013). The results were expected because the power source is centrally located therefore, dissipation will begin from centre and spread outward as seen in Fig. 2. As a result, the fins around the centre of the heat source will have the maximum temperature recorded amongst the other fins. From Fig. 2, the heat flow is determined significantly by the arrangement of the fins. In Fig. 2, concentric circles of heat maps can be seen to start from the middle of the heat sink and flow outward. The heat maps are regular likewise the concentric circles due to the regular arrangement of the fins. This observation suggests that a smart arrangement of the fins can improve the dissipation of heat in the preferred direction, thereby separating hot and cold zones which could help microelectronics product engineers in their designs. In Fig. 2, it is seen that the orientation of the plate fins tend to bias the conduction profile from the usual concentric circles around the heat source to concentric ellipses.

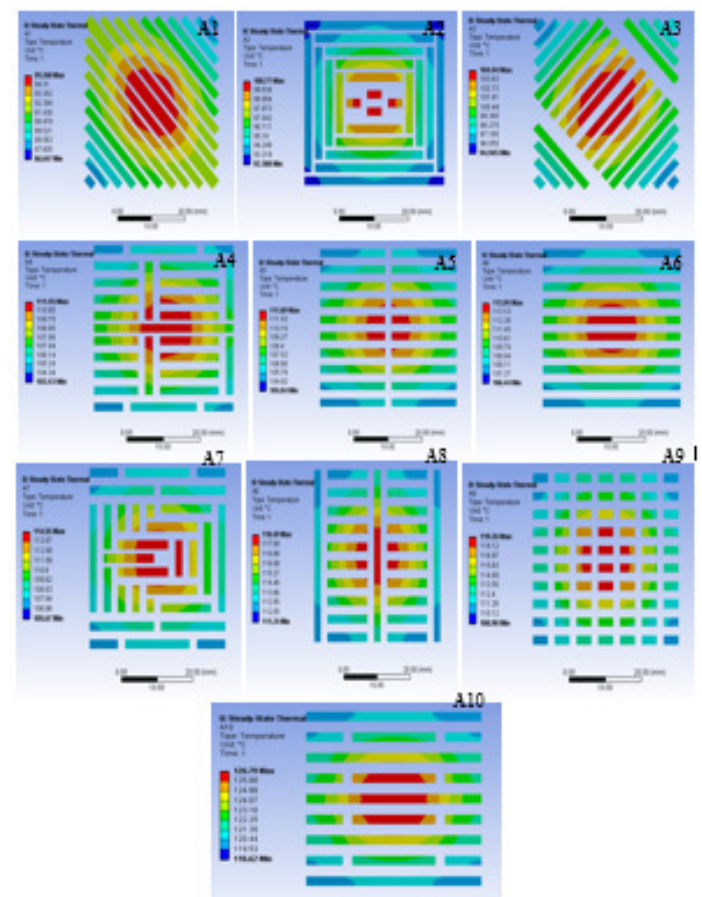

Fig. 2: Temperature Contour Plots (Time is in seconds)

This has led to significant improvement in the thermal efficiency of the heat sinks. The most bias conduction profile could be seen in A1 which is the most thermal efficient heat sink arrangement. Also, the symmetric distribution of short-span fins at the centre of A2 leads to significant improvement in thermal efficiency for less biased conduction profile. In addition, the orientation of the plate fins in A3 tends to bias the conduction profile in the direction of the plates. Also, A10 showed the least biased conduction profile. All heat concentrated in the middle, resulting to the least thermal efficient heat sink. These pieces of evidence therefore are vital design considerations when choosing heat sinks and a preferred conduction profile.

Thermal Analysis: Fig. 3 presents the maximum temperature of the A1-A 10 rectangular heat sink fins arrangement. Fig. 3 showed that fin arrangement A1 recorded the lowest maximum temperature while A10 recorded the highest maximum temperature. However, the temperature increased from A1 to A10 according 
to the arrangement of the fins. The thermal resistance $(R)$ of the fins arrangement was calculated using Eq. 2.

$$
R=\Delta T / Q
$$

Where $\Delta T=T_{m}-T_{a}$, and $T_{m}$ and $T_{a}$ are the maximum and ambient temperature respectively. $Q$ is the heat flow in watts (W). The resulting thermal resistances for the A1-A10 fins arrangement is presented in Fig. 4.

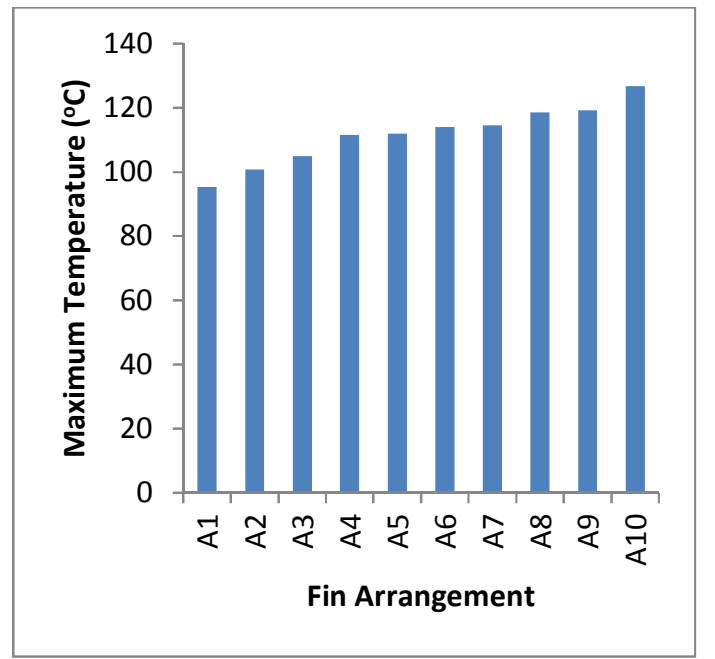

Fig. 3: Maximum temperature for fin arrangement

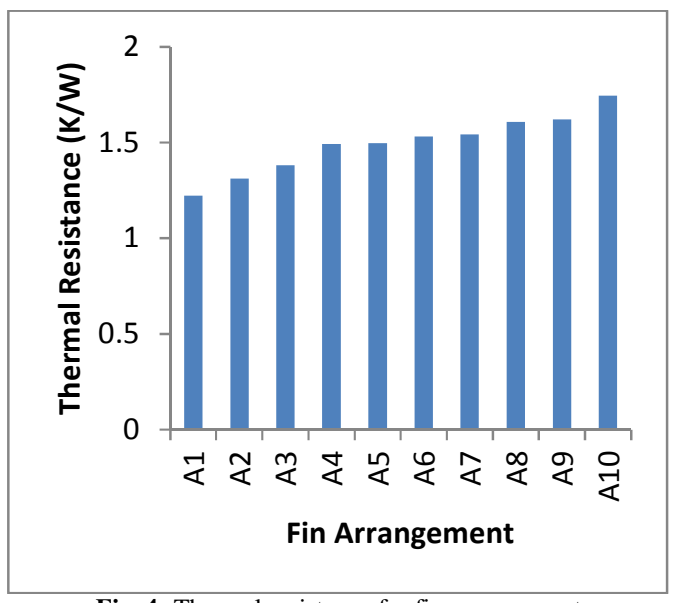

Fig. 4: Thermal resistance for fin arrangement

In Fig. 4, it is observed that the thermal resistance increases from A1 to A 10 with A1 the lowest and A10 the highest. Also the thermal efficiency of the A1-A10 fins arrangement is presented in Fig. 5. It is observed in Fig. 5 that the thermal efficiency of the fins arrangement increases from A10 to A1. A1 fins arrangement recorded the highest thermal efficiency while A10 recorded the lowest thermal efficiency. From the analysis of the fins, it could be inferred that A1 fins arrangement exhibited a better thermal characteristics, followed by A2 through to A10. In addition, A1 fins arrangement will be recommended for use in heat sinks based on the criteria of this research. The arrangements considered here are just a few of many possible configurations that can be investigated. A further study is required to assess comprehensively the effect of heat sink arrangements on the thermal conduction path and findings from such work shall inform design of heat sinks to optimized heat conduction paths thus ensuring significant improvement in thermal efficiency of heat sinks.

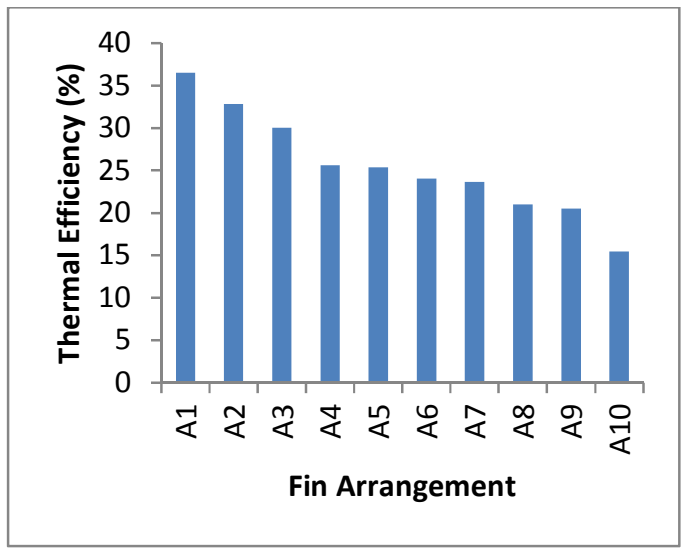

Fig. 5: Thermal efficiency for fin arrangement

Conclusions: The steady state thermal analyses of a flat plate heat sink was investigated focusing on the rectangular fins arrangement. Factors like temperature, thermal resistance and thermal efficiency should be considered when designing a heat sink device. In addition, the research suggested that fins arrangement with the least thermal resistance and highest efficiency will exhibit better thermal performance characteristics. However, the choice of a particular heat sink fins arrangement may largely depend on the engineer and customer demand.

\section{REFERENCES}

Ekpu, M; Bhatti, R; Ekere, N; Mallik, S; Otiaba, K (2012). Effects of thermal interface materials (solders) on thermal performance of a microelectronic package. IEEE Int. Symposium on Design, Test, Integration, and Packaging of MEMS/MOEMS, Cannes Cote d' Azur, France, 25-27 April 2012. 154-159.

Ekpu, M; Bhatti, R; Ekere, NN; Mallik, S; Amalu, E; Otiaba, KC (2011). Investigation of Effects of Heat Sinks on Thermal Performance of Microelectronic Package. $3^{\text {rd }}$ IEEE International Conference on Adaptive Science and Technology. Abuja, Nigeria 2426 November 2011. 127-132. 
Ekpu, M; Bhatti, R; Okereke, MI; Mallik, S; Otiaba, KC (2013). Prediction and Optimization of Design Parameters of Microelectronic Heat Sinks. J. Emerg. Trend. Eng. Appl. Sci. (JETEAS). 4 (3): 493 - 500.

Incropera, FP; Dewitt, DP; Bergman, TI; Lavine, AS (2007). Fundamentals of heat and mass transfer. $6^{\text {th }}$ Ed. United States of America, John Wiley and Sons, Inc. 2 -925 .

Kreutz, EW; Pirch, N; Ebert, T; Wester, R; Ollier, B; Loosen, P; Poprawe, R (2000). Simulation of microchannel heat sinks for optoelectronic microsystems. Microelectron. J. 31 (9-10): 787-790.

Kulkarni, DP; Das, DK (2005). Analytical and numerical studies on microscale heat sinks for electronic applications. Appl. Therm. Eng. 25 (1415): $2432-2449$.

Luo, X; Xiong, W; Cheng, T; Liu, S (2009). Design and optimization of horizontally located plate fin heat sink for high power LED street lamps. Elect. Comp. Tech. Conf. $854-859$.
Maveety, JG; Jung, HH (2000). Design of an optimal pin-fin heat sink with air impingement cooling. Int. Commun. Heat Mass Transfer. 27 (2): 229 - 240.

Maveety, JG; Jung, HH (2002). Heat transfer from square pin-fin heat sinks using air impingement cooling. IEEE Trans. Comp. Packag. Tech. 25 (3): 459 -469 .

Naphon, P; Sookkasem, A (2007). Investigation on heat transfer characteristics of tapered cylinder pin fin heat sinks. J. Ener. Con. Manage. 48 (10): 2671 2679.

Wan, ZM; Liu, J; Su, KL; Hu, XH; M, SS (2011). Flow and heat transfer in porous micro heat sink for management of high power LEDs. Microelectron. $J$. 42 (5): $632-637$.

Yang, Y; Peng, H (2008). Numerical study of pin-fin heat sink with un-uniform fin height design. Int. J. Heat Mass Transfer. 51 (19-20): 4788 - 4796.

Yang, Y; Peng, H (2009). Numerical study of the heat sink with un-uniform fin width designs. Int. J. Heat Mass Transfer. 52 (15 - 16): 3473 - 3480. 